\title{
Shape your career: opportunities for Early Career Members in 2022 and the experience of applying for an ERS fellowship
}

\author{
Cristina Ardura-Garcia ${ }^{1,6}$, Dario Kohlbrenner $\mathbb{1}^{2,3,4,6}$ and Joana Cruz $\mathbb{1}^{5}$
}

${ }^{1}$ Institute of Social and Preventive Medicine, University of Bern, Bern, Switzerland. ${ }^{2}$ Faculty of Medicine, University of Zurich, Zurich, Switzerland. ${ }^{3}$ Dept of Pulmonology, University Hospital Zurich, Zurich, Switzerland. ${ }^{4} \mathrm{HP} 2$ Laboratory, INSERM, Grenoble Alpes University, Grenoble, France. ${ }^{5}$ Center for Innovative Care and Health Technology (ciTechCare), School of Health Sciences (ESSLei), Polytechnic of Leiria, Leiria, Portugal. ${ }^{6}$ These authors contributed equally.

Corresponding author: Joana Cruz (joana.cruz@ipleiria.pt)

Shareable abstract (@ERSpublications)

In this article, we present the @EuroRespSoc opportunities for ECMs (@EarlyCareerERS) in the upcoming year and describe the experience of applying for an ERS Fellowship, with the key steps and challenges identified https://bit.ly/3nz5KIO

Cite this article as: Ardura-Garcia C, Kohlbrenner D, Cruz J. Shape your career: opportunities for Early Career Members in 2022 and the experience of applying for an ERS fellowship. Breathe 2022; 18: 210218 [DOI: 10.1183/20734735.0218-2021].
Copyright @ERS 2022

Breathe articles are open access and distributed under the terms of the Creative Commons Attribution Non-Commercial Licence 4.0.

Received: 22 Oct 2021 Accepted: 11 Jan 2022

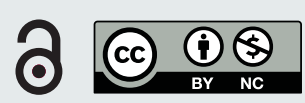

The European Respiratory Society (ERS) is the largest scientific and clinical organisation in respiratory medicine in Europe, with more than 35000 members from around the world with different but complementary backgrounds. The society is committed to providing enriching opportunities to early career members (ECMs) who are pursuing a career in the respiratory field by offering opportunities for funding, skills and career development, networking, and much more. In this article, we provide an overview of the opportunities for ECMs to become involved in ERS activites in 2022, as well as a testimonial from one of the ERS long-term research fellowship awardees in 2021, where key steps and challenges of the application process are outlined.

Opportunities for ECMs in the coming year (Cristina Ardura-Garcia, Switzerland, on behalf of the ECMC)

The ERS offers multiple opportunities for ECMs in many different areas, such as fellowships and awards specially targeted at young researchers, session chairing, article writing, active involvement in ERS working groups, or participation in task forces and clinical research collaborations. Here we present a summary of the main opportunities for ECMs that the ERS has to offer.

\section{Funding opportunities}

The ERS has four different programmes to fund and support ECMs' projects in respiratory science and medicine (table 1). The grants aim to facilitate the necessary training to help ECMs move their careers forward and develop as the future leaders in respiratory research. The four programmes are aimed at different stages of early career researcher, and they all promote knowledge exchange through mobility between institutions both within Europe and overseas.

- Short-term research fellowship: this programme funds projects that are 1-3 months long that researchers wish to undertake in a research institution outside their home country, to learn a new research technique. There is no age limit and applications from researchers who have had a career break (e.g. parental leave, unemployment, or a period working outside research) are encouraged. The host institution may be located in Europe or overseas. There are normally two rounds per year, although the April and October 2021 calls were cancelled due to the COVID-19 pandemic. The next deadline for the next call will be in October 2022.

- Long-term research fellowships: this programme is similar to the short-term research fellowship, but the projects are 6-12 months long. Again, there is also no age limit to apply. The host institution may be in Europe or overseas, and there is also an expectation of knowledge gain through new research 
TABLE 1 ERS fellowships and funding opportunities

\begin{tabular}{|c|c|c|c|c|}
\hline & $\begin{array}{l}\text { Short-term research } \\
\text { fellowship }\end{array}$ & $\begin{array}{l}\text { Long-term research } \\
\text { fellowship }\end{array}$ & $\begin{array}{c}\text { RESPIRE Marie } \\
\text { Skłodowska-Curie fellowship }\end{array}$ & Clinical Training \\
\hline $\begin{array}{l}\text { Duration, } \\
\text { months }\end{array}$ & $1-3$ & $6-12$ & $24-36$ & $1-6$ \\
\hline $\begin{array}{l}\text { Fellowship } \\
\text { aim }\end{array}$ & $\begin{array}{l}\text { Pursuing clinical, translational } \\
\text { or basic research }\end{array}$ & $\begin{array}{l}\text { Pursuing clinical, translational } \\
\text { or basic research }\end{array}$ & $\begin{array}{l}\text { Pursuing clinical, translational or } \\
\text { basic research }\end{array}$ & $\begin{array}{l}\text { Learning clinical skills or } \\
\text { procedures }\end{array}$ \\
\hline $\begin{array}{l}\text { Candidate } \\
\text { profile }\end{array}$ & $\begin{array}{c}\text { MD, MSc, PhD, MD-PhD or } \\
\text { equivalent }\end{array}$ & $\begin{array}{c}\text { MD, MSc, PhD, MD-PhD or } \\
\text { equivalent }\end{array}$ & $\begin{array}{c}\mathrm{PhD} \text { or } 4 \text { years of research } \\
\text { experience }\end{array}$ & $\begin{array}{l}\text { MD or qualified healthcare } \\
\text { professionals }\end{array}$ \\
\hline Host institute & $\begin{array}{l}\text { Any institute in Europe or } \\
\text { abroad }^{\#}\end{array}$ & $\begin{array}{l}\text { Any institute in Europe or } \\
\text { abroad }^{\#}\end{array}$ & $\begin{array}{l}\text { Any institute in Europe or } \\
\text { abroad }^{\#}\end{array}$ & Any institute in Europe \\
\hline Deadline & 3 October 2022 & Cancelled for 2022 & 1 May 2022 & 3 October 2022 \\
\hline
\end{tabular}

techniques that are not available in the home institution. The application includes the submission of all supporting documents on the online application platform and an interview for shortlisted candidates, after initial ranking of the applications. The programme runs once a year, although the 2022 call has been cancelled due to COVID-19 pandemic. The next call is expected in 2023.

- Marie Skłodowska-Curie postdoctoral research fellowships (RESPIRE): this ERS fellowship is aimed at more advanced early career researchers with either a $\mathrm{PhD}$ or 4 years or full-time research experience. The fellowship lasts for 24 months if undertaken in a host institution in Europe. If based overseas, the fellowship covers a 36-month-long project, including a return phase to Europe, which may be at the applicant's original home institution. The return phase is usually 12 months and aims to ensure knowledge transfer and reintegration into the European Research Area. Host institutions need to pre-register in the RESPIRE Web Host Registry. The fellowship programme receives funding from the European Union (EU) Horizon 2020 research and innovation programme under the Marie Skłodowska-Curie grant agreements No. 847462 (MSCA COFUND scheme). The deadline for the third call of the RESPIRE4 fellowships is 1 May 2022.

- Clinical training fellowships: this programme is aimed at early career clinicians who wish to learn a new skill or procedure which is not available at their home institution. It covers visits to a European host institution outside their home country lasting between 1 and 6 months. As for the short-term research fellowships, there are two rounds per year, although the April and October 2021 calls were cancelled due to COVID-19 pandemic. The next deadline for the next call will be in October 2022.

More information about the fellowships is available at: https://www.ersnet.org/education-and-professionaldevelopment/funding-opportunities-fellowship-programmes/. Due to the COVID-19 pandemic the budget available for the fellowships and the mobility of researchers have been seriously affected and some of the calls were cancelled. Hopefully the situation will improve soon, and some calls could be re-opened as normal in the near future.

\section{Awards}

Every year the Early Career Member Committee (ECMC) selects an outstanding ECM to receive the ECM award. Applicants can self-nominate or they may be nominated by another ERS member. The award is given on the basis of potential for future contribution to the respiratory research field, main career achievements, and previous active contribution and engagement towards the ERS. Applications are assessed through a peer-review process by the ECMC, with the endorsement of the Science Council and Executive Committee of the ERS. Interviews with past ECM awardees can be found in previous early career forum articles [1, 2]. The next call will be open from December 2022 to mid-February 2023 and the results will be announced in May 2023.

Several assemblies and groups offer awards for the best abstracts, although these may vary from year to year. There is also the possibility to apply for a travel award if submitting an abstract to the ERS International Congress.

\section{Representation in the ERS}

Each of the 14 assemblies have one ECM representative who is selected every 3 years in an open voting system. The 14 ECM representatives form the ECMC. Apart from representing the ECMs of their assembly, each member of the ECMC has another role(s) to ensure that ECMs are represented in each of 
the society's working groups and councils. For example, they are part of the Science Council, the Education Council, or the Fellowships and Awards Working Group. An overview of the ECMC structure and tasks is provided in a previous early career forum article [3]. Being an ECMC representative is a unique opportunity to network and establish collaborations with both senior and junior ERS colleagues and leadership.

\section{Other opportunities}

There are many other ways in which ECMs can take an active role within the ERS. During the International Congress, all poster discussion sessions are now co-chaired by an ECM together with a senior ERS member, and many oral presentation sessions are also co-chaired by ECMs. In addition, ECMs can participate as invited speakers and propose sessions for the International Congress, such as Symposia and Hot Topics, together with other senior colleagues.

Outside of the International Congress, the ERS organises many other activities, such as research seminars, webinars and podcasts, which can be either proposed or chaired by ECMs, and where they can also appear as invited speakers. Testimonials from ECMs who have had the experience of organising an ERS Research Seminar are described elsewhere [4]. The ECMs have also been involved as chairs at the Lung Science Conference, the Sleep and Breathing Conference and at the 2021 Virtual Academy in Adult and Paediatric Respiratory Medicine.

Currently, all the ERS Task Forces and Clinical Research Collaborations include ECMs among their members. These provide unique opportunities for ECMs to learn, for example, how to develop a guideline following a standardised ERS procedure, under the direct guidance and supervision of senior respiratory researchers.

Finally, interested ECMs may also participate in article writing through the ERS via multiple types of Breathe articles, such as the Journal club, Landmark papers in respiratory medicine or Doing science. Furthermore, each year the ECM representatives prepare an article on the Highlights of the ERS Congress for each Assembly. This article is written by ECMs supervised by the chairs of each group within the Assemblies and published in ERJ Open Research.

To conclude, ECMs who are eager to take on a more active role within the ERS have many opportunities to do so. Interested ECMs should regularly update their competence list via myERS (https://my.ersnet.org/) and contact the ECM representative of their Assembly to inform them of their interests.

Testimonial about the experience of preparing an ERS fellowship application (Dario Kohlbrenner, Switzerland)

I feel more than privileged to be among the awardees of an ERS long-term research fellowship for 2021. The fellowship enabled me to conduct a 1-year postdoctoral research stay at the HP2 Laboratory, University of Grenoble Alpes, France, where I was investigating the effects of intermittent normobaric hypoxia on cardiorespiratory performance and vascular reactivity in healthy elderly participants.

There are many interesting, but challenging steps to complete before finally hitting the "submit" button on the ERS fellowships website. Here, I reflect on some of these steps and challenges. I hope that my thoughts will support some of the future applicants and provide a little guidance in their preparation process. The ERS fellowships website provides guidelines on the documents to be submitted and their content. Therefore, I will not cover the deliverables and rather focus on the process of preparation.

In brief, the procedure up to the submission of the application contains three stages: identification, preparation, and application. Table 2 summarises, from my experience, important points to consider and approaches to deal with them. In the text, I focus on resources across all preparation stages that helped me preparing the application.

\section{The goals}

Being the awardee of an ERS fellowship is a tremendous chance to shape our careers. It enables us to conduct unique research, learn new skills and techniques, and build our international network. Even before I decided to apply for an ERS fellowship, I developed a detailed career plan. This plan covered my career goals (i.e. skills and competences, positions) alongside a timeline of when I wanted to have achieved them. Upon completion of the plan, which I consider a constantly adapting tool, I started to explore the funding options. The ERS fellowship turned out to be the perfect fit for my goals and qualifications. I can recommend thinking about career goals and opportunities early in your career (e.g. at the beginning of 
TABLE 2 Preparation stages towards the submission of an application for an ERS fellowship and some key points to address the challenges

\begin{tabular}{|c|c|c|c|}
\hline & Identification & Preparation & Application \\
\hline Key points & $\begin{array}{l}\text { - Plan early } \\
\text { - Network with staff at the } \\
\text { host lab (postdocs, PhD } \\
\text { students, technicians) } \\
\text { - Find funding for a } \\
\text { short-term visit }\end{array}$ & $\begin{array}{l}\text { - Let your application rest for some days and then revise } \\
\text { it, this gives you a fresh perspective } \\
\text { - Ask peers and patients to review your application } \\
\text { - Network with previous fellowship recipients }\end{array}$ & $\begin{array}{l}\text { - Do not forget to celebrate your } \\
\text { submission } \\
\text { - Conduct several interview training } \\
\text { sessions with peers, the host, and your } \\
\text { home institution }\end{array}$ \\
\hline
\end{tabular}

your $\mathrm{PhD}$ or $\mathrm{MD}$ journey). I am convinced that a focus on goals helps to stay on track during all preparation phases, from identifying a host institution, to project planning, and conducting the research.

\section{The network}

A fantastic thing about being a researcher is the fact that you get to know numerous inspiring people from all over the globe. I took advantage of my network and asked for advice on various topics. Specifically, I had chats with two previous ERS fellowship recipients, a postdoctoral fellow at my host institution, and a senior researcher I admire for his impressive research career. I am convinced that these exchanges were a key factor towards my successful application, and I cannot thank my network enough for their support. Think broadly about your network, peers may also provide precious hints on the experience of moving abroad and support your fellowship interview preparations. Furthermore, a patient in the field you are about to research may provide unique feedback on the feasibility and clinical relevance of your project. Finally, the ERS fellowship team are happy to help applicants with the desire to network.

\section{The perfect fit}

I will use this section as a concluding thought since it is intertwined with the previous ones. I thought about my application as a package. I wanted the package to include multiple components: it should fit and advance my field of research including immediate translations into clinical practice; the findings of the work should also shape training of respiratory healthcare staff; and at the same time, the project and the stay should develop my career (i.e. learning new skills and techniques, engage in teaching, taking responsibility for a project) and enhance my international network. I considered my package to be satisfyingly prepared as soon as it incorporated all these points. From my point of view, the outstanding packages are those which are the most complete and individually tailored. Applicants who return to their home institution after the fellowship might, for example, consider future long-term collaborations with the host institution and describe this idea in the application.

I wish all future applicants the best of success in building their package towards the perfect fit!

\section{Concluding remarks}

In this article, we identified the upcoming opportunities for ECMs to become involved in the ERS and provided tips on how to be successful when applying for an ERS fellowship. Keep up to date with the latest news about ERS opportunities by following us on Twitter (@EuroRespSoc and @EarlyCareerERS) and/or Facebook (@EuropeanRespiratorySociety, ERS Early Career Members group).

Acknowledgements: J. Cruz acknowledges the support of the Center for Innovative Care and Health Technology (ciTechCare) of the Polytechnic of Leiria, which is funded by Portuguese national funds provided by Fundação para a Ciência e Tecnologia (FCT) (UIDB/05704/2020 and UIDP/05704/2020).

Conflict of interest: C. Ardura-Garcia reports receiving grants or contracts from the Swiss National Science Foundation (SNSF320030_182628) and The Swiss Lung Association (2019-03_641670), outside the submitted work. D. Kohlbrenner has nothing to disclose. J. Cruz has nothing to disclose. 


\section{References}

1 Janssens T, Burgy O, Rolandsson Enes S, et al. In the spotlight: first ERS Early Career Member Award winner, the ERS Lung Science Conference 2020 and new ECMC members. Breathe 2019; 15: 330-336.

2 Martinez Alejos R, Harrison SL, Crespo A, et al. In the spotlight: Early Career Member Awardee 2020, ERS Lung Science Conference 2021, and Sleep and Breathing 2021. Breathe 2020; 16: 200199.

3 De Brandt J. Insight into the structure and tasks of the Early Career Members Committee of the European Respiratory Society. Breathe 2020; 16: 200046.

4 Collins JJP, Bartel S, Ubags ND, et al. A sneak peek into the Early Career Members' session at the ERS International Congress and the experience of organising an ERS Research Seminar. Breathe 2020; 16: 200012. 